\title{
Fanconi Mutation in Macrophage Activation Syndrome
}

\author{
Sidharth Yadav ${ }^{1} \cdot$ Anu Maheshwari $^{1}\left[\right.$ ] $\cdot$ Shreshtha Kaushik ${ }^{1} \cdot$ Deonath Mahto $^{1}$
}

Received: 15 March 2021 / Accepted: 28 May 2021 /Published online: 15 July 2021

(c) Dr. K C Chaudhuri Foundation 2021

To the Editor: Macrophage activation syndrome (MAS) is a potentially life-threatening complication occurring mainly in systemic juvenile idiopathic arthritis (SOJIA) and is considered to be an acquired form of familial hemophagocytic lymphohistiocytosis (fHLH) [1]. Prevalence of MAS has been reported to be around $10 \%$ in patients of SOJIA while subclinical cases to be as high as $30 \%-40 \%$ [2]. Mortality rate in MAS has been reported to be $8 \%$ [3].

We encountered a patient who presented with 2 wk of fever with serositis, bilateral knee joint effusion, lymphadenopathy and hepatosplenomegaly. She was diagnosed with SOJIA, as per the International League of Associations for Rheumatology (ILAR) criteria. In view of fever, hyperferritinemia, transamnitis, thrombocytopenia, hypertriglyceridemia, and hypofibrinogenemia, diagnosis of MAS in the setting of SOJIA was made. We found mutation in gene SLX4 (-), location exon 5, variant c.1127C>G ( $p$. Ala376Gly); heterozygous for Fanconi anemia complementation group $P$, which has not been reported yet for SOJIA with MAS. This mutation has been linked to increased chromosomal instability and is present in children with congenital bone marrow failure syndromes.

The fHLH is a syndrome of aberrant immune activation and is usually associated with mutations in the perforindependent cytolytic pathway. It is expected that the children with SOJIA who develop MAS may have a similar genetic predisposing mutation. PRF1 mutation (perforin gene) has been reported in $15 \%-40 \%$ of patients with fHLH [1]. Other reported genetic mutations in fHLH are STX11(Syntaxin 11), STXBP2 (Munc 18-2), LYST (Lysosomal trafficking regulator), $R A B 27 A$ (Rab27a), $A P 3 B 1$ (AP-3) [4].

Anu Maheshwari

dranugulati@gmail.com

1 Department of Pediatrics, Lady Hardinge Medical College and associated Kalawati Saran Children Hospital,

New Delhi, India
We conclude that children with SOJIA who present with MAS may have an underlying mutation in perforin gene or other genetic defects associated with congenital bone marrow failure syndromes. As MAS has high morbidity and mortality, it may be prudent to get mutation studies, which will help in guiding the management and prognostication, especially in children $<5$ y of age.

\section{Declarations}

Conflict of Interest None.

\section{References}

1. Ravelli A, Minoia F, Davi S, et al. Classification criteria for macrophage activation syndrome complicating systemic juvenile idiopathic arthritis: a European League Against Rheumatism/ American College of Rheumatology/Paediatric Rheumatology International Trials Organisation Collaborative Initiative. Arthritis Rheumatol. 2016;68:566-76.

2. Behrens EM, Beukelman T, Paessler M, Cron RQ. Occult macrophage activation syndrome in patients with systemic juvenile idiopathic arthritis. J Rheumatol. 2007;34:1133-8.

3. Minoia F, Davi S, Horne A, et al. On behalf of the Pediatric Rheumatology International Trials Organization, the childhood Arthritis and Rheumatology research alliance, the Pediatric Rheumatology collaborative study group, and the Histiocyte Society. clinical features, treatment, and outcome of macrophage activation syndrome complicating systemic juvenile idiopathic arthritis: a multinational, multicenter study of 362 patients. Arthritis Rheumatol. 2014; 66:3160-9.

4. Crayne CB, Albeituni S, Nichols KE, Cron RQ. The immunology of macrophage activation syndrome. Front Immunol. 2019;10:119.

Publisher's Note Springer Nature remains neutral with regard to jurisdictional claims in published maps and institutional affiliations. 